IdeAs

Idées d'Amériques

18 | 2021

Frontières dans les Amériques - Intégration, sécurité

et migrations

\title{
Bicentenario de Centroamérica
}

David Díaz Arias

\section{(2) OpenEdition \\ Journals}

Edición electrónica

URL: https://journals.openedition.org/ideas/11508

DOI: $10.4000 /$ ideas. 11508

ISSN: 1950-5701

Editor

Institut des Amériques

Referencia electrónica

David Díaz Arias, «Bicentenario de Centroamérica», IdeAs [En línea], 18 | 2021, Publicado el 01 octubre 2021, consultado el 21 octubre 2021. URL: http://journals.openedition.org/ideas/11508 ; DOI: https:// doi.org/10.4000/ideas. 11508

Este documento fue generado automáticamente el 21 octubre 2021

\section{(c) (1) $\odot)$}

IdeAs - Idées d'Amériques est mis à disposition selon les termes de la licence Creative Commons Attribution - Pas d'Utilisation Commerciale - Pas de Modification 4.0 International. 


\title{
Bicentenario de Centroamérica
}

\author{
David Díaz Arias
}

1 En medio de una severa crisis económica, mientras se enfrenta a una nueva y temible ola de la pandemia por Covid-19, con escándalos de corrupción, con dudas sobre la concreción y el futuro de las instituciones democráticas, con migraciones que reflejan el fracaso económico y político de varios de sus países, con una agresiva aceleración de reformas neoliberales y con denuncias de autoritarismo y corrupción, Centroamérica alcanza, en 2021, 200 años de independencia política ${ }^{1}$. No parece, así expuesto, un buen contexto para cumplir un aniversario tan significativo. En ese sentido, en su Bicentenario, esta región debe bregar entre sus problemas históricos, los nuevos deterioros contemporáneos y la necesidad de encontrar formas de unidad, entre las que el pasado compartido siempre ha sido un buen recurso.

2 De esa forma, parece imperioso conmemorar los dos siglos de independencia. Pero, ¿qué tipo de vínculos con el pasado se pueden recordar en este difícil contexto? ¿Cuáles pasados conmemorar para construir unidad y no división? ¿Cómo celebrar el pasado recorrido en este presente tan imperioso? En este artículo se exploran, en forma comparada para la región centroamericana, algunas de las respuestas a estas preguntas.

\section{Los pasados evocados}

3 Los gobiernos centroamericanos y Chiapas (Tuxtla y Comitán pertenecieron al reino de Guatemala antes de 1821) han resaltado la coyuntura conmemorativa ofrecida por el Bicentenario, para presentarse a sí mismos como un parteaguas en la historia. En enero del 2021, los diputados salvadoreños declararon, como si hubiera necesidad de un decreto así, el año del Bicentenario para memorar la independencia centroamericana, "lo cual constituye un hecho histórico de gran relevancia para la República de El Salvador"2. Antes de eso, en los otros países del istmo se habían constituido comisiones a las que se les encargó preparar las celebraciones: en Costa Rica se instituyó desde octubre de 2018, mientras que en Nicaragua se creó en agosto de 2020, en Honduras y Panamá en septiembre, en Guatemala en octubre y en Chiapas en noviembre de ese 
mismo año. Así, exceptuando la costarricense, las otras comisiones se crearon en medio del contexto de alerta de salud global y con el impacto de la crisis económica.

4 El Bicentenario, en ese sentido, ha enfrentado dos grupos que fueron definidos por las políticas públicas con respecto a la pandemia: aquellos que pugnaban por una celebración pomposa que hiciera que el mundo se fijara en el istmo y su conmemoración, y, por otro lado, un grupo que se oponía a cualquier tipo de actividad celebratoria que pusiera más en riesgo a la ciudadanía. De hecho, en la semana en que se trazaba la ruta hacia el 15 de septiembre, los casos por Covid-19 crecieron exponencialmente en todos los países de la región (al respecto, los datos de Nicaragua no son fiables) y la lista de muertos por la enfermedad creció. Debido a esa situación, no parecía que el contexto era el correcto para celebraciones.

5 A mediados de agosto, el periódico La Prensa Libre de Guatemala recomendó sobriedad y emprender acciones de reforma política cuyo impacto juzgaba más importante que cualquier festejo: "como por ejemplo un cambio de conducta en las actuales autoridades de gobierno que lleve a abandonar los secretismos, la opacidad y el dispendio del erario"3. Ya desde junio, El Heraldo de Honduras también había comentado que la situación no era para celebrar, pero sí "valorar nuestra historia"

6 El caso nicaragüense es todavía más problemático, en vista de que ese país experimentaba desde abril de 2018 una tremenda represión a los movimientos opositores al régimen de Daniel Ortega Saavedra; dicha persecución se intensificó a medida que avanzó el 2021, de forma que el régimen envió a prisión a todos los candidatos de partidos opositores que representaran alguna competencia electoral para su fórmula presidencial. ¿Qué pasado recordar en Nicaragua? Desde septiembre de 2020, el diario opositor La Prensa de Nicaragua sentenció que era un "infortunio histórico" que los caudillos y tiranos siguieran dominando el país y que solo por un milagro Nicaragua se salvaría de celebrar el Bicentenario "sometida a una dictadura brutal y corrupta que tiene un irracional afán de perpetuidad" lamentablemente, fue una realidad; el ingeniero Ulises José Morales lo formuló con claridad en un artículo de opinión el 11 de septiembre, en el que señaló que el Bicentenario que debía ser una "magna celebración de unidad nacional y fervor patriótico", con una fiesta pomposa, era en cambio vivido en medio de una "dictadura partidaria y familiar", que se apoyaba en la "brutalidad de la represión y las armas", con "cárceles repletas de presos políticos y con una economía al borde del precipicio".

7 El Salvador, también dividido por el autoritarismo de su presidente Nayib Bukele, se enrumbó al Bicentenario con dudas sobre las posibilidades de unidad nacional. El 21 de agosto, José Miguel Fortín Magaña, exdirector del Instituto de Medicina Legal, se adhirió a la idea de festejar los doscientos años con "una festividad llena de patriotismo, pero frugal y sin ostentación", pero, en su lugar, siguiendo un lenguaje similar al guatemalteco, denunciaba que no había nada que celebrar porque los "animales de rapiña aúllan desde el gobierno y se preparan como carroñeros que son para devorar lo poco que queda al destruir la Constitución"7.

8 En Costa Rica, a pesar de la similitud en los problemas generados por la crisis, los festejos del Bicentenario adquirieron un sentido de necesidad. A inicios de septiembre de 2021, un periodista le hizo la consulta al presidente Carlos Alvarado Quesada de esta manera: “¿Cómo conciliar el merecido festejo de algo como el Bicentenario con un país que está con el ánimo caído, tanto por la pandemia como por la situación económica? ¿Tenemos derecho a celebrar en esas circunstancias?”. A pesar de que podría haber 
sorteado bien la pregunta, dando una respuesta negativa, Alvarado indicó que era merecida la celebración porque "estamos celebrando no solo lo actual sino 200 años y han pasado cosas muy buenas en estos 200 años" recurso del pasado para justificar el presente.

9 En Panamá, la celebración del Bicentenario se planificó para noviembre del 2021. Es posible, por eso, que la pandemia le dé un respiro a esas celebraciones en comparación con las de los otros países de Centroamérica.

\section{Las celebraciones}

10 Casi cualquier actividad organizada por algún estado centroamericano en 2021 fue insertada en el motivo del Bicentenario. Por eso, no es difícil advertir, a pesar de las restricciones, una abultada agenda conmemorativa. Si se presta atención esencialmente al mes festivo más importante para los cinco países de la Centroamérica histórica (Panamá tendrá en noviembre el grueso de las celebraciones sobre su bicentenario), se encuentran similitudes, pero también diferencias atrayentes.

11 Ciertamente, lo primero que llama la atención de estas festividades es su dimensión "virtual". En Chiapas, la organización sin fines de lucro "Bicentenario de Chiapas, A.C." creó un sitio electrónico (http://bicentenariochiapas.org) con el plan conmemorativo, las actividades, artículos vinculados con el evento y exposición virtual de algunos eventos históricos. El Ministerio de Cultura y Deportes de Guatemala desarrolló un portal electrónico (https://mcd.gob.gt/bicentenario/) dedicado al bicentenario, con un cronómetro que realizaba un conteo por días, horas, minutos y segundos hacia la medianoche del 14 de septiembre; en ese espacio virtual, Guatemala se reclamó como “tierra milenaria, cuna de la cultura Maya” y, por eso, una nación con 200 años de independencia y tres mil "años de Riqueza Cultural”. En Honduras, los diarios La Prensa y El Heraldo montaron un hermoso portal denominado "Bicentenario de Independencia" (https://bicentenariohonduras.hn/), lleno de recursos de multimedia, con rostros de escogidos próceres de la emancipación encabezados por Francisco Morazán, artículos históricos, datos sobre Honduras "en el mundo" y con adivinanzas sobre la historia de Honduras. Menos atrayente, el portal desarrollado por el gobierno de El Salvador (http://sansalvador.gob.sv/BicentenarioSs) se contentó con incluir noticias sobre el Bicentenario, mientras que el gobierno de Nicaragua no creó ningún portal. El gobierno de Costa Rica también montó un bonito portal (https://200costarica.go.cr/), lleno de vídeos, imágenes, mensajes, calendario de eventos y actividades y con tres cronómetros que caminaban hacia la "celebración Patria" (iniciada desde la primera hora del 14 de septiembre), la "Firma del Acta de Independencia" (identificada como un acta firmada en Cartago el 29 de octubre de 1821) y la "Firma del Pacto de Concordia" (una primera constitución política firmada el 1 de diciembre de 1821). El gobierno de Panamá también creó su propio portal web (https://www.bicentenariopma.com/), con cronómetro, diversos recursos multimedia y formas de interacción.

12 En su conjunto, estos espacios virtuales mostraron una imagen muy local de la independencia, centrada en cada país, sin alusiones a la región centroamericana (ni siquiera en información), sin hipervínculos entre ellos y con una visión celebrativa de la historia que no incluye ni críticas ni narrativas complejas. En el caso de Chiapas, además, esa visión localista se complementó en las celebraciones presenciales con la idea de que Comitán siempre había sido parte de la historia de México; así, el 
presidente mexicano Andrés Manuel López Obrador señaló en un discurso oficial el 28 de agosto, que "Chiapas ha estado siempre presente en las transformaciones de México", saltando cualquier referencia a su pertenencia colonial. El otro elemento sobresaliente en esos sitios es la ausencia de un debido contexto que legitime el tono conmemorativo, pues no se presentan datos que permitan comparar el ayer con el hoy, para dar constancia del avance. Un posicionamiento así, hay que subrayarlo, jamás hubiera sido el del centenario de la independencia (1921), ni el del sesquicentenario (1971), cuando el mensaje conmemorativo estaba lleno de "evidencia" del avance al contrastar el presente con el pasado.

Por supuesto, lo virtual también incluyó conciertos, conferencias, mesas redondas, conversatorios, exposiciones artísticas e incluso, en Costa Rica, la opción de seguir paso a paso el recorrido de la antorcha de la independencia a través de una aplicación que muestra un mapa interactivo (https://antorchavirtual.mep.go.cr/app/escritorio.html) señalando el camino de la antorcha y creado por Ministerio de Educación Pública.

¿Se redujeron las festividades a manifestaciones electrónicas? No. Especialmente el 15 de septiembre y reducidos limitadas a ciudades principales, se produjeron algunas actividades presenciales como desfiles reducidos (nada parecido a los grandes desfiles militares y escolares que ocurrían antes de las medidas de higiene pública contra la Covid-19), actos cívicos, se izaron las banderas nacionales en diferentes edificios, se llevaron ofrendas florales a estatuas y monumentos de los héroes nacionales, eventos con drones y los políticos aprovecharon la celebración para dar discursos a su favor y para llamar a la unidad nacional. La actividad desarrollada por la Municipalidad de San José en el Estadio Nacional de Costa Rica la noche del 15 de septiembre fue una extraordinaria muestra festiva que se transmitió por los canales televisivos y por redes sociales (https://www.youtube.com/watch?v=e_WNhL771hM\&t=4984s).

Pero la conmemoración también atrajo cuestionamientos. En Chiapas, la Coordinadora Nacional de Trabajadores de la Educación (CNTE) siguió a López Obrador en su gira por ese estado, para protestar contra el presidente mexicano ${ }^{10}$. En muchos lugares de Guatemala se produjeron manifestaciones en contra del gobierno y de la conmemoración; en la Plaza de la Constitución en Guatemala, varios grupos indígenas reprodujeron una ceremonia maya, en la que un líder indicó: "Desde los pueblos, antes de la invasión española, antes de los 200 años, hemos celebrado la vida, agradeciendo a la Madre Tierra [...]. Esto es una manifestación en contra del Bicentenario, porque eso fue cuando se constituyó esta república, que ha sido de mucho racismo, discriminación, exclusión"11. En El Salvador, una gran multitud, compuesta de una diversa cantidad de grupos, se lanzó a la calle para protestar contra el gobierno de Nayib Bukele y las reformas que desarrolló en semanas anteriores y que algunos consideraron como atentados a la democracia salvadoreña ${ }^{12}$. Así, el Bicentenario dejó muestras de una región que, 200 años después, sigue atascada en las discusiones sobre la integración y el futuro que comenzaron en 1821.

\section{Conclusión}

La conmemoración del Bicentenario de la Independencia en Chiapas y Centroamérica ha estado marcada por la pandemia por Covid-19, pero también por las divisiones internas con que este aniversario encuentra a la región. Las manifestaciones del 15 de septiembre contra Bukele en El Salvador probablemente sean las más visibles, pero, en 
general, hay un descontento en el istmo que se visualiza por los cuestionamientos a las clases políticas, las denuncias de corrupción, la falta de claridad en las decisiones de combate a la pandemia, y el deterioro de las frágiles instituciones democráticas. Los 200 años básicamente se celebraron de manera virtual, como una especie de metáfora de lo virtual del desarrollo democrático de esta región en estos dos siglos.

Lo anterior es muy importante, además, en una sociedad local y global dominada por la tiranía del presentismo que la pandemia por Covid-19 ha acentuado. Centroamérica, en ese sentido, cumple con el problema anotado por el historiador francés François Hartog de que "sin futuro y sin pasado, el presentismo genera diariamente el pasado y el futuro de quienes, día tras día, tienen necesidades y valoran lo inmediato" ${ }^{13}$. Internamente, además, nos encontramos con una Centroamérica rota en sentido simbólico y en sentido social. Simbólico, porque los recursos oficiales del recuerdo no han servido para enfrentar los conflictos que dividen a esta sociedad; social, porque esos conflictos tienen raíces históricas que los vuelven imponentes y difíciles de resolver si no se sigue un modelo de inclusión en beneficio de las mayorías.

\section{BIBLIOGRAFÍA}

Díaz Arias, David, La independencia de Costa Rica. Historia, debate y conmemoración, 1821-2021, San José (Costa Rica), EUNED, 2021

Díaz Arias, David y Viales Hurtado, Ronny, “El impacto del covid-19 y otras 'pandemias' contemporáneas en Centroamérica”, en Gerardo Gutiérrez Cham, Susana Herrera Lima y Jochen Kemner (coords.), Pandemia y crisis: el covid-19 en América Latina, Guadalajara, Editorial Universidad de Guadalajara, 2021, p. 86-117

Fumero Vargas, Patricia, Festejos y símbolos: el primer centenario de la independencia de Centroamérica (1921), San José, EUCR, 2021

Hartog, François, Regímenes de historicidad. Presentismo y experiencias del tiempo, México, Universidad Iberoamericana, 2007

Lara-Martínez, Rafael, El Bicentenario. Un enfoque alternativo, San Salvador, Editorial Universidad Don Bosco, 2011

Martí Puig, Salvador, “América Central, bicentenario en crisis”, Política Exterior, Vol. 35, № 200, 2021, p. 136-142

Programa Estado de la Nación, Sexto Estado de la Región 2021: versión ampliada, San José (Costa Rica), CONARE - PEN, 2021

\section{NOTAS}

1. Programa Estado de la Nación. Resumen sexto estado de la región 2021. San José, Costa Rica, CONARE-PEN, 2021. Se puede revisar en: https://repositorio.conare.ac.cr/bitstream/handle/ 
20.500.12337/8137/PEN_informe_estado_region_resumen_2021.pdf?sequence=1\&isAllowed=y (página revisada el 11 de septiembre de 2021).

2. Marilú Alvarenga, "Diputados declaran el 2021 como “Año del Bicentenario de la Independencia de El Salvador y los Acuerdos de Paz", Portal de la Nueva Asamblea Legislativa, El Salvador: https://www.asamblea.gob.sv/node/10968 (página revisada el 12 de septiembre de 2021).

3. Redacción, "Editorial: Prospectiva bicentenaria", La Prensa Libre (Guatemala), 15 de agosto de 2021, https://www.prensalibre.com/opinion/editorial/prospectiva-bicentenaria/ (página revisada el 11 de septiembre de 2021).

4. Redacción, "Honduras, bicentenario con visión de futuro", El Heraldo (Honduras), 8 de junio de 2021: https://www.elheraldo.hn/pais/1469259-466/honduras-bicentenario-con-visión-de-futuro (página revisada el 11 de septiembre de 2021).

5. Redacción, “Rumbo al Bicentenario", La Prensa (Nicaragua), 16 de septiembre de 2020: https:// www.laprensa.com.ni/2020/09/16/editorial/2721275-rumbo-al-bicentenario (página revisada el 11 de septiembre de 2021).

6. Ulises José Morales, “A propósito del Bicentenario", La Prensa (Nicaragua), 11 de septiembre de 2021: https://www.laprensa.com.ni/2021/09/11/opinion/2877799-a-proposito-del-bicentenario (página revisada el 11 de septiembre de 2021).

7. José Miguel Fortín Magaña, “Nada que celebrar en septiembre”, La Prensa Gráfica (El Salvador), 21 de agosto de 2021: https://www.laprensagrafica.com/opinion/Nada-que-celebrar-enseptiembre-20210820-0072.html (página revisada el 11 de septiembre de 2021).

8. Víctor Fernández, "Los tres ticos de los 200 años, según el Presidente", Revista Dominical, 12 de septiembre de 2021, p. 8-11.

9. Andrés Manuel López Obrador, "Discurso del presidente Andrés Manuel López Obrador en el Bicentenario de la Independencia de Chiapas de la Corona Española, desde Comitán de Domínguez", Sitio oficial de AMLO, 28 de agosto de 2021: https://lopezobrador.org.mx/ 2021/08/28/discurso-del-presidente-andres-manuel-lopez-obrador-en-el-bicentenario-de-laindependencia-de-chiapas-de-la-corona-espanola-desde-comitan-de-dominguez/ (página revisada el 21 de septiembre de 2021).

10. Redacción, "CNTE vuelve a protestar en acto de AMLO; niega chantaje y exige 'diálogo con soluciones'”, Animal Político, 28 de agosto de 2021: https://www.animalpolitico.com/2021/08/ cnte-protesta-amlo-niega-chantaje-pide-dialogo-soliciones/ (página revisada el 21 de septiembre de 2021).

11. Douglas Cuevas y Henry Montenegro, "Bicentenario: los mensajes, manifestaciones e imágenes que marcaron la conmemoración de los 200 años de independencia en Guatemala", Prensa Libre, 15 de septiembre de 2021: https://www.prensalibre.com/guatemala/comunitario/ bicentenario-los-mensajes-manifestaciones-e-imagenes-que-marcaron-la-conmemoracion-delos-200-anos-de-independencia-en-guatemala/ (página revisada el 15 de septiembre de 2021).

12. "15 de septiembre: El Salvador marcha contra el autoritarismo", Portal de DW Akademie: https://www.dw.com/es/15-de-septiembre-el-salvador-marcha-contra-el-autoritarismo/ a-59185624 (página revisada el 15 de septiembre de 2021).

13. François Hartog, Regímenes de historicidad. Presentismo y experiencias del tiempo, México, Universidad Iberoamericana, 2007, p. 140-141. 


\section{AUTOR}

\section{DAVID DÍAZ ARIAS}

David Díaz Arias (costarricense) es Ph.D. en Historia por Indiana University (Estados Unidos) y M.Sc. en Historia por la Universidad de Costa Rica. Es catedrático y director del Centro de Investigaciones Históricas de América Central de la Universidad de Costa Rica. Ha ganado el Premio Nacional a la Investigación Cultural y el Premio Cleto González Víquez. Sus últimos libros son: Chicago Boys del Trópico: Historia del Neoliberalismo en Costa Rica, 1965-2000 (San José, Costa Rica: EUCR, 2021) y La independencia de Costa Rica: historia, debate y conmemoración, 1821-2021 (San José, Costa Rica: EUNED, 2021). 